\title{
Libros y edición
}

\author{
Books and publishing
}

Se ha visto en los últimos tiempos que la revolución de lo digital modifica de alguna forma las posibilidades del acceso al conocimiento. Además, transforma profundamente las modalidades de las argumentaciones y los criterios o recursos que pueden movilizar al lector a aceptar o rechazar dichas argumentaciones. En tal caso, la textualidad electrónica permite desarrollar las argumentaciones o las demostraciones según una lógica que ya no necesariamente es lineal o deductiva, sino que puede ser abierta, expandida y relacional gracias a la multiplicación de vínculos hipertextuales.

Es en ese momento y en este nuevo escenario, cuando la concepción del artefacto-libro que se tenía antes -el modelo tradicional de libro impreso, inmutable, de sistema cerrado que se contiene a sí mismo y que requiere grandes esfuerzos para extenderse más allá de sus ataduras-, queda corta y no alcanza a cubrir las exigencias de las múltiples posibilidades. Lo que en realidad está ocurriendo aquí tiene consecuencias muy profundas, puesto que se trata de una mutación epistemológica que transforma las modalidades de construcción y acreditación de los discursos del saber. Esto abre nuevas perspectivas a la adquisición de los conocimientos otorgada por la lectura, razón por la cual esta revolución está creando un nuevo sistema de publicación y distribución que está alterando sensiblemente la forma de consumir contenidos.

El camino ha perdido su fluidez debido al mal enfoque que se le ha dado a las cuestiones que aparecen con el fenómeno de esta mutación epistemológica. Para entrar en el medio, por ejemplo, se ha tratado de responder a la pregunta: “¿cómo hago digitales los libros?» en lugar de poner énfasis en lo que verdaderamente se debería responder: «¿cómo lo digital afecta a los libros?» y a partir de allí encontrar una fórmula futura para el libro en la que se abstraiga la idea tradicional del libro de las formas tradicionales de publicación y consumo.

En efecto, ahora lo que hay que tener en cuenta del libro son las relaciones entre ideas y recipientes, entre el escritor y el lector, entre los lectores y otros lectores y dejar de lado un poco la compulsión por creer que la magia de un libro se encuentra solo en su superficie; pues el libro del futuro ya no es aquel sistema cerrado ni inmutable, como asume Craig Mod - en su artículo del 2011 "Libros y edición posartefacto: el efecto de lo digital en la manera en que producimos, distribuimos y consumimos contenidos"-, es etéreo e interconectado, y se manifiesta públicamente aquí y allá. Es un artefacto «completo» solo por un mínimo instante, ya que se transforma deliberadamente. Está cubierto por capas con los comentarios al margen que compartimos. Reclama un vínculo con la promesa de comunidad implícita en su forma. Ser digitales le permite a los libros ser anotados, marcados, subrayados, ver sus esquinas dobladas, ser resumidos, citados, hipervinculados, compartidos, recordados, y que se dialogue con ellos e incluso mucho más.

Lo digital cambia la relación entre los lectores y los escritores, y la hace más directa. El público y el autor entran en diálogo precozmente. Los escritores pueden calibrar el interés de los lectores a medida que la historia se desarrolla y decidir qué temas merece la pena desarrollar con mayor amplitud. De hecho, las intervenciones de los lectores, algunas veces indirectas, pueden manifestarse en el producto de autoría final. Sin embargo, ahora que los lectores permanentemente le hacen un seguimiento al autor en sus blogs o páginas de las redes sociales, pueden mantener un contacto más directo y de esta relación pueden obtenerse también algunas veces productos bastante fructíferos. No sobra además mencionar las ventajas con respecto a la promoción de sus libros. 
Otro punto es que lo digital obliga a que una publicación se genere rápidamente. La información debe salir lo más pronto posible. Esto modifica la relación que antes había del libro con el tiempo y el espacio, ya que al disminuirse el tiempo en el que sale una publicación, simultáneamente también puede combatirse las barreras que antes existían en la adquisición. La cuestión del tiempo del mismo modo tiene sus repercusiones, pues muchas veces la calidad se ve afectada por la premura con la que se publica. Sin embargo, en este caso lo digital también tiene una vía de escape y es que cabe la posibilidad de corregir en línea.

Finalmente, el temor a los cambios y el dejar atrás plataformas que se creía perfeccionadas es lo que impide la exploración y luego evolución de los nuevos medios o dispositivos que podrían revolucionar o no el mundo de la lectura. Los modelos tradicionales e inmutables siempre pueden permanecer en los escenarios cambiantes como tesoros a los que se aferran algunos románticos. Estos modelos funcionarían bien para consumidores de nicho. No obstante, personalmente considero que aún falta un buen tiempo para que los libros físicos se conviertan en minoría. La tecnología y el desarrollo del libro en papel han sido bastante sólidos como garantes de la conservación de la memoria del hombre. El entorno digital por el contrario, adolece de la fragilidad en la conservación de los datos y falta aún desarrollo en los soportes. Pero para lo que viene, hay que tener la mente abierta a las múltiples posibilidades y no atascarse en lo que se creyó siempre que fue lo mejor.

Isabel Cristina Serna Salazar Editorialista invitada 